\title{
Diagnosis of latent Mycobacterium tuberculosis infection: tuberculin test versus interferon-gamma release
}

\author{
Thaís Furtado Ferreira'[1],[2], Pollyanna da Fonseca Silva Matsuoka[1],[2], \\ Alcione Miranda dos Santos ${ }^{[1],[3]}$ and Arlene de Jesus Mendes Caldas ${ }^{[1,[4]}$
}

[1]. Programa de Pós-Graduação Stricto Sensu em Saúde Coletiva, Universidade Federal do Maranhão, São Luis, Maranhão, Brasil. [2]. Secretaria Municipal de Saúde, São Luis, Maranhão, Brasil. [3]. Departamento de Saúde Pública, Universidade Federal do Maranhão, São Luis, Maranhão, Brasil. [4]. Departamento de Enfermagem, Universidade Federal do Maranhão, São Luis, Maranhão, Brasil.

\begin{abstract}
Introduction: The treatment of individuals with active tuberculosis (TB) and the identification and treatment of latent tuberculosis infection (LTBI) contacts are the two most important strategies for the control of TB. The objective of this study was compare the performance of tuberculin skin testing (TST) with QuantiFERON-TB Gold In TUBE® in the diagnosis of LTBI in contacts of patients with active TB. Methods: Cross-sectional analytical study with 60 contacts of patients with active pulmonary TB. A blood sample of each contact was taken for interferon-gamma release assay (IGRA) and subsequently performed the TST. A receiver operating characteristic curve was generated to assess the cutoff points and the sensitivity, predictive values, and accuracy were calculated. The agreement between IGRA and TST results was evaluated by Kappa coefficient. Results: Here, $67.9 \%$ sensitivity, $84.4 \%$ specificity, $79.1 \%$ PPV, $75 \%$ NPV, and $76.7 \%$ accuracy were observed for the $5 \mathrm{~mm}$ cutoff point. The prevalence of LTBI determined by TST and IGRA was $40 \%$ and $46.7 \%$, respectively. Conclusions: Both QuantiFERON-TB Gold In TUBE $®$ and TST showed good performance in LTBI diagnosis. The creation of specific diagnostic methods is necessary for the diagnosis of LTBI with higher sensitivity and specificity, preferably with low cost and not require a return visit for reading because with early treatment of latent forms can prevent active TB.
\end{abstract}

Keywords: Tuberculosis. Diagnosis. Latent tuberculosis. Interferon-gamma.

\section{INTRODUCTION}

Latent tuberculosis infection (LTBI) is defined as the period between infection with Mycobacterium tuberculosis (MBT) and the onset of tuberculosis (TB) disease. LTBI detection is a well established TB control strategy recommended by the World Health Organization (WHO) ${ }^{(1)}$; it enables infected individuals who are at greater risk of progression to active disease to commence with drug treatment.

It is estimated that one third of the world's population is infected with MTB, mostly in its latent form, constituting an important reservoir for disease reactivation ${ }^{(2)}$. This pool is sufficient for the long-term generation of new TB cases, even if the transmission chain is interrupted ${ }^{(3)}$.

Identification and treatment of LTBI can reduce the risk of active disease development by $90 \%^{(4)(5)}$. Contact with patients with active pulmonary TB increases the risk of infection,

\footnotetext{
Corresponding autor: Dra. Thaís Furtado Ferreira. Avenida 06, Quadra 10, Casa 51, Turu, 65066-730 São Luis, Maranhão, Brasil.

Phone: 5598 98125-0200

e-mail: tatafurtadof@hotmail.com

Received 3 August 2015

Accepted 10 November 2015
}

especially when the diagnosis is delayed. Approximately $30 \%$ of those who come in contact with pulmonary TB patients are infected; of these, $5 \%$ develop active TB within two years and another 5\% develop the disease 2 years post infection ${ }^{(6)(7)}$.

In most situations of contact with MTB, the host immune response is sufficient to prevent disease; the bacteria may be completely destroyed or a state of latency could be established. Individuals who remain infected exhibit positive tuberculin skin testing (TST) but are asymptomatic. In addition, microbiological tests for MBT are negative and chest X-rays show no changes. Occasionally, the immune response is not effective, resulting in active TB due to a primary infection or the reactivation of a state of latency ${ }^{(8)}$. Bacilliferous patients who come in close or casual contact with active TB are considered to have an increased risk of developing LTBI and therefore must be tested ${ }^{(5)}$.

In Brazil, LTBI individuals are diagnosed mainly by means of a positive TST associated with the exclusion of TB disease. Previous studies have demonstrated the advantages of TST including the technical ease of the method and its low cost. However, its specificity can be affected by false-positive results due to previous vaccination with Bacille Calmette-Guerin (BCG) or non-tuberculous mycobacteria infection ${ }^{(9)(10)}$. Moreover, the sensitivity of TST may be reduced in various situations such as pregnancy, malnutrition, sarcoidosis, malignant neoplasms, and immunosuppression related to infection by the human immunodeficiency virus (HIV) $)^{(11)}$. 
Because of the limitations of TST, interferon-gamma release assays (IGRAs), which measure the production of interferongamma (IFN- $\gamma$ ) in response to stimulation by specific MTB antigens (ESAT-6, CFP-10, and TB7.7), have been developed. Of these, QuantiFERON-TB Gold In TUBE® has been shown as the most effective in the diagnosis of LTBI compared with TST. In addition, since the BCG vaccine does not influence assay outcome, IGRAs are very useful in countries where BCG is administered post infancy or in cases of repeated boosters. Moreover, this method requires only a single visit to perform the examination ${ }^{(5)(12)(13)(14)(15)}$.

Studies comparing the two tests (IGRAs and TST) have demonstrated that IGRAs exhibit higher specificity and limited sensitivity, but cannot distinguish between active TB and LTBI, especially in populations subject to BCG vaccination, and therefore are more recommended for the diagnosis of LTBI $^{(12)(13)(14)(15)(16)}$. Thus, in this study, we compared the performance of TST with QuantiFERON-TB Gold In TUBE $®$ in the diagnosis of LTBI in contacts of bacilliferous pulmonary TB patients. It is hoped that this study to analyze the performance of the TST in the diagnosis of LTBI as the incorporation of IGRAs in clinical practice seem unfeasible due to its high cost.

\section{METHODS}

A cross-sectional analytical study was conducted with contacts of bacilliferous pulmonary TB-positive patients treated at a referral hospital in São Luis, State of Maranhão, Brazil.

Samples were obtained from the contacts of 48 active tuberculosis index cases identified through the laboratory log book from April 2012 to May 2013 (Figure 1). All patients with active pulmonary TB and positive sputum smear microscopy were considered as index cases ${ }^{(11)}$.

During consultation with the specialist doctor (pulmonologist), the index cases were instructed on the importance of evaluating their household contacts and meetings were scheduled with these contacts. A household contact was defined as anyone living in the same domicile with the index case for more than 6 hours/day for a period $\geq 3$ months at the time of TB diagnosis ${ }^{(11)}$.

The study included all asymptomatic household contacts aged over 18 years of both sexes with no history of TB or prior treatment with isoniazid. Pregnant or lactating women and contacts that were vaccinated with $B C G \leq 2$ years or that exhibited respiratory symptoms, positive HIV serology, changes in their chest $\mathrm{X}$-rays, and any immunosuppressive disease were excluded.

During the meeting the contacts were offered information regarding active and latent $\mathrm{TB}$ and presented with the study proposal. All contacts who agreed to participate in the study signed an Informed Consent form and subsequently underwent a chest X-ray and a rapid HIV test (Rapid Check ${ }^{\circledR}$ HIV 1/2). Contacts with an abnormal chest X-ray and/or positive rapid HIV test were excluded from the study. It should be emphasized that only one contact showed changes in the chest X-ray and was excluded from the study.
Up to two contacts were selected per index case to avoid selection bias. When the index case had more than two eligible contacts, which happened in only five cases, a random selection was performed by a simple draw. In total, the study sample consisted of 60 household contacts.

Participants who met the inclusion criteria completed a structured questionnaire that was administered individually by a previously trained interviewer and consisted of the following variables: gender (male, female); age (in years); type of kinship with the index case [mother, father, spouse (a), brother (sister), cousin (a), uncle (a)]; time between symptom onset and TB diagnosis in the index case; presence of BCG scar; time of completion of BCG vaccination; nature of contact with the index case (intradomiciliary, extradomiciliary); and whether the participant slept in the same room with the index case (Yes, No).

Following completion of the questionnaire, $3 \mathrm{ml}$ of peripheral blood was collected from each participant, then packaged and stored for performing the IGRA (QuantiFERON-TB Gold In TUBE®) according to the manufacturer's instructions (Cellestis Ltd., Carnegie, Victoria, Australia) ${ }^{(17)}$. Next, TST was conducted using the antigen and technique recommended by the Ministry of Health of Brazil ${ }^{(11)}$.

The TST reading was performed 48 hours post application using a specific millimeter ruler and measuring the largest transverse diameter of induration perpendicular to the forearm; the results were recorded in millimeters, even in the absence of induration $^{(11)}$. Contacts with a result $\geq 5 \mathrm{~mm}$ were considered as LTBI carriers by TST. The TST reading was performed by two trained raters and the Kappa coefficient was used to estimate the inter-rater agreement. The TST readings were conducted for all contacts on a previously scheduled day.

The amount of INF- $\gamma$ was measured by enzyme-linked immunosorbent assay (ELISA). The results were analyzed using the QuantiFERON-TB Gold In TUBE® software provided by the manufacturer and expressed as UI/ml IFN- $\gamma$. Contacts with positive results were referred for consultation with a medical specialist at the referral hospital.

The TST and QuantiFERON-TB Gold In TUBE® assays were performed independently by different professionals without any knowledge of the other test results.

Data were collated and analyzed using the STATA program version 11.0. A descriptive analysis was performed based on the calculation of means and standard deviation (numerical) and frequencies (categorical). A significance level of 5\% was adopted.

The cutoff points for TST were determined using a Receiver Operating Characteristic (ROC) curve (Figure 2). Although there is no gold standard detection method for LTBI, QuantiFERON-TB Gold In TUBE® was used in this study to elucidate the operational characteristics of IGRA and TST. The sensitivity, specificity, positive predictive value (PPV), negative predictive value (NPV), and accuracy were calculated for the identified cutoff points. Sensitivity was defined as the ratio between TST positive results and positive IGRA results; specificity was defined as the ratio of negative TST and negative 


\section{Patients with positive sputum smear \\ microscopy (index case) \\ $\mathrm{n}=\mathbf{4 8}$}

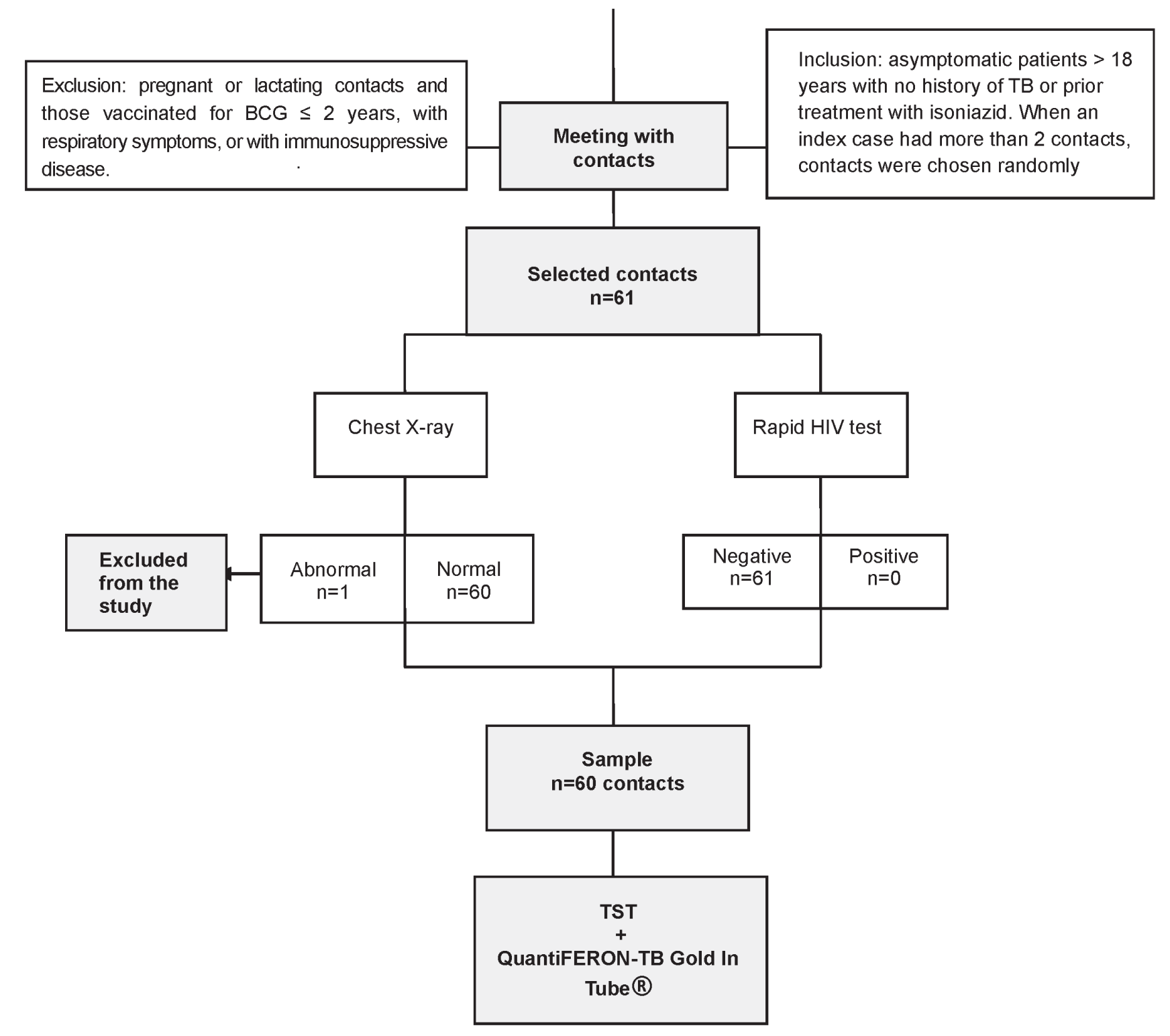

FIGURE 1 - Flowchart of study design. BCG: Bacillus Calmette-Guérin; TST: tuberculin skin testing.

IGRA results; PPV was calculated as the proportion of TST positive participants who were also IGRA positive; NPV was calculated as the proportion of TST negative participants who were also IGRA negative; and accuracy was calculated as the ratio between the total number of correct results (sum of true positive and true negative) and the total number of participants.

The prevalence of LTBI determined using QuantiFERONTB Gold In TUBE® was calculated as the number of participants with positive results, divided by the total number of participants, multiplied by one hundred [(number of positive participants/ total number of participants) $\mathrm{x}$ 100]. The prevalence of LTBI determined by TST was calculated as the number of participants with TST $\geq 5 \mathrm{~mm}$ divided by the total number of participants, multiplied by one hundred [(number of positive participants with TST $\geq 5 \mathrm{~mm} /$ total number of participants) $\times 100]$. The agreement between the QuantiFERON-TB Gold In TUBE® and TST results was evaluated using the Kappa coefficient. The Kappa test was interpreted according to Landis and $\operatorname{Koch}^{(18)}$ : $<0.40$, weak agreement; 0.40 to 0.75 , moderate agreement; $>0.75$, good agreement. 


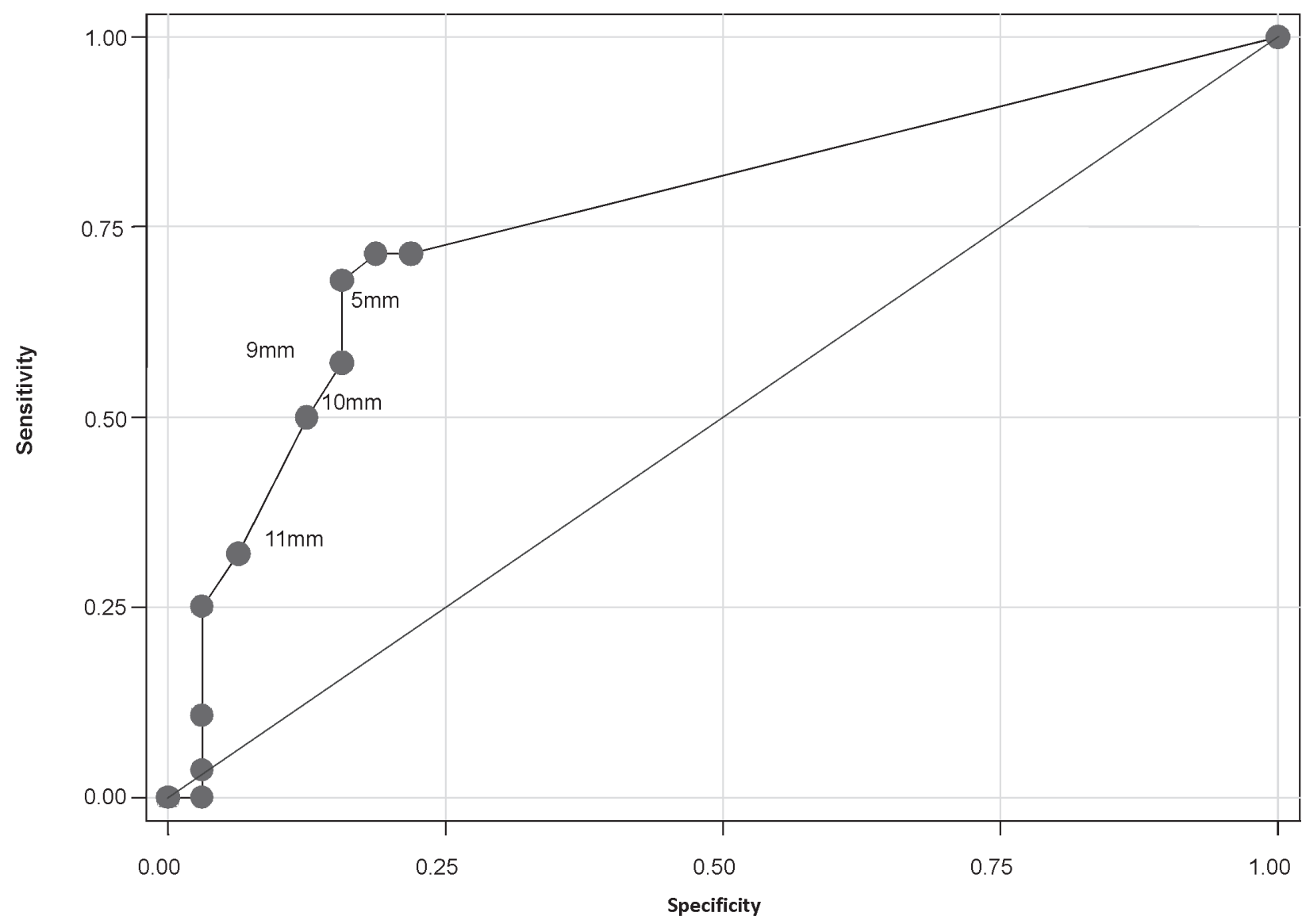

Area under the ROC curve $=0.7651$

FIGURE 2 - ROC curve for determination of TST cut-off point (in millimeters). São Luis, State of Maranhão, Brazil, in 2013. ROC: Receiver Operating Characteristic; TST: tuberculin skin testing.

The study was evaluated and approved by the Ethics Committee in Research of the University Hospital of the Federal University of Maranhão (CEP/UFMA) under embodied opinion n. 240/11, in accordance with Resolutions 196/96 and 466/12. The procedures followed were in keeping with the Helsinki Declaration of 1964, as revised in 1975, 1983, 1989, 1996, and 2000.

\section{RESULTS}

Most of the 60 evaluated contacts were female (75\%) with a mean age of 37 years $( \pm 12.18) ; 35 \%$ were partners of the index case; $88.3 \%$ had household contact with the index case; $58.3 \%$ slept in the same room with the index case; $86.7 \%$ had only one BCG vaccination scar while the rest (13.3\%) had none. The average time between symptom onset and the diagnosis of TB in the index case was 87.63 days ( \pm 88.97$)$.

Table 1 details the sensitivity, specificity PPV, NPV, and accuracy for the different TST cutoff points. The best cutoff point was $5 \mathrm{~mm}$, with $67.9 \%$ sensitivity, $84.4 \%$ specificity, $79.1 \%$ PPV, $75 \%$ NPV, and $76.7 \%$ accuracy. Of the 60 contacts, $46.7 \%$ were positive for LTBI based on the QuantiFERON-TB Gold In TUBE ${ }^{\circledR}$ test and $40 \%$ were TST positive. The agreement between the TST and QuantiFERON-TB Gold In TUBE® results was $76.7 \%$ (Kappa coefficient $=0.5270$; $\mathrm{p}$ value $\leq 0.001$; Table 2) ${ }^{(18)}$.

\section{DISCUSSION}

The results of this study indicate that the $5 \mathrm{~mm}$ cutoff exhibited enhanced sensitivity, predictive values, and accuracy. Previous studies suggest that reducing the TST cutoff point leads to increased sensitivity and decreased test specificity. Although using a more sensitive cutoff point increases the risk of mistakenly diagnosing an individual as an LTBI carrier, the benefits of treatment appear to outweigh the risks; adverse reactions to isoniazid are rare and the risk of selection for resistant strains during the treatment of index case contacts is minimal since the bacillary population is $10 w^{(6)}$.

Takenami et al. ${ }^{(19)}$ demonstrated that $70.3 \%$ of contacts were identified as positive using QuantiFERON-TB Gold In TUBE® while only $52.5 \%$ were detected by TST. Machado et al. ${ }^{(20)}$ 
TABLE 1 - Sensitivity, specificity, positive predictive value, negative predictive value, and accuracy of tuberculin skin testing in predicting latent tuberculosis in pulmonary tuberculosis contacts. São Luis, State of Maranhão, Brazil, 2013.

\begin{tabular}{lccccc}
\hline TST $(\mathbf{m m})$ & Sensitivity e (\%) & Specificity (\%) & PPV (\%) & NPV (\%) & Accuracy (\%) \\
\hline$\geq 5$ & 67.9 & 84.4 & 79.1 & 75.0 & 76.7 \\
$\geq 9$ & 57.1 & 84.4 & 76.1 & 69.2 & 71.7 \\
$\geq 10$ & 50.0 & 87.5 & 77.7 & 66.6 & 70.0 \\
$\geq 11$ & 32.1 & 93.7 & 81.8 & 61.2 & 65.0 \\
\hline
\end{tabular}

TST: tuberculin skin testing; PPV: positive predictive value; NPV: negative predictive value.

found an agreement of $76 \%(\mathrm{k}=0.53)$ between the TST and QuantiFERON-TB Gold In TUBE® results among the household contacts of patients with active TB; these findings confirm the results of this study.

In countries with a high TB burden, treatment of active TB is the top priority for disease control. The second priority is the identification and treatment of individuals with LTBI, since this practice can reduce the risk of progression to active TB by $90 \%{ }^{(4)}$. The goal of TST and IGRAs tests is to identify individuals who are at increased risk of reactivation or of a new infection by MBT, such as the contacts examined in this study.

The guidelines of the Center for Disease Control and Prevention (CDC) in Europe do not recommend the use of IGRAs in countries with a high incidence of $\mathrm{TB}^{(21)}$. In addition, TST appears to be the most viable option in low-and middle-income countries because of its low $\cos ^{(22)(23)(24)(25)}$. However, although TST has been extensively studied, there is still some discrepancy between the optimal TST cutoff point for LTBI diagnosis and subsequent isoniazid treatment recommended by the Ministry of Health $(\geq 5 \mathrm{~mm})^{(11)}$ and the professional practice $(\geq 10 \mathrm{~mm})$.

Previous studies have shown that the sensitivity of QuantiFERON-TB Gold In TUBE® and TST is approximately $80 \%^{(26)}$. However, IGRAs has a specificity $>95 \%$ in the diagnosis of LTBI ${ }^{(22)(26)}$. The specificity of TST is affected by previous BCG vaccination; specificity values reach $97 \%$ in unvaccinated populations, while in populations extensively vaccinated with $\mathrm{BCG}$, it is approximately $60 \%{ }^{(22)}$. However, BCG vaccination administered up to the age of one does not interfere with TST results after 10 years $^{(26)(27)}$.

According to the World Atlas of BCG Policies and Practices ${ }^{(28)}$, BCG vaccination was introduced in Brazil in 1976 as a single dose vaccine administered at birth. Subsequently, changes in procedure were introduced such as the institution of booster doses in 1994, a practice that was then banned in 2006. Notwithstanding, in this study, over $80 \%$ of the participants had a history of BCG vaccination at birth.

PPV denotes the probability of a true infection; the higher the risk of exposure, as in cases of close contact with patients with active TB, the greater the $\mathrm{PPV}^{(29)}$.

False-negative TST results can be explained by exposure time; a period of 6-8 weeks post exposure to MBT is necessary for LTBI screening. The longer the time period between
TABLE 2 - Kappa Index for tuberculin skin testing (TST) and QuantifERON-TB Gold In TUBE®. São Luis, State of Maranhão, Brazil, in 2013.

\begin{tabular}{lccc}
\hline \multirow{2}{*}{ Tuberculin test } & \multicolumn{3}{c}{ QuantiFERON-TB Gold } \\
\cline { 2 - 4 } & positive & negative & total \\
\hline Positive & 19 & 5 & 24 \\
Negative & 9 & 27 & 36 \\
\hline Total & $\mathbf{2 8}$ & $\mathbf{3 2}$ & $\mathbf{6 0}$ \\
\hline
\end{tabular}

Kappa $=0.5270 \mathrm{p}<0.001 \mathrm{CI}: 95 \%$.

exposure and testing, the greater the agreement between the TST and the QuantiFERON-TB Gold In TUBE® results ${ }^{(30)(31)}$. Our results indicate that the average period of incubation in the index cases was 87.63 days ( \pm 88.97 ), which might explain the statistical difference between the PPV and NPV observed for participants with an induration $\geq 9 \mathrm{~mm}$.

Our study sample consisted mainly of household contacts, mostly index case partners, with a high risk of infection due to the increased degree of exposure. This finding corroborates with the results of previous studies; Gazzetta et al. ${ }^{(32)}$ demonstrated that $69.3 \%$ of contacts had a very close degree of kinship to the index case (father, mother, children, siblings, and partner) and that because of their proximity to the focus they were at high risk of becoming infected. Kipfer et al. ${ }^{(33)}$, identified a correlation between proximity/exposure time and LTBI following the detection of pulmonary TB in a Swiss army training camp. The QuantiFERON-TB Gold In TUBE® (IGRA) diagnosis was positive in $93 \%$ of the individuals who shared the same dorm with the index case.

The limitation of this study is that TST was not repeated eight weeks later in contacts that had an induration $\leq 5 \mathrm{~mm}$; initially negative contacts could present an increase of $10 \mathrm{~mm}$ compared to their first results, which could explain the positive results obtained using QuantiFERON-TB Gold In TUBE® (IGRA) and the negative TST results. An additional limitation is the possible small sample size. A strong point of the study is the involvement of index case contacts from the State of Maranhão, Northeastern Brazil, which has high rates of TB incidence $(29 / 100,000 \mathrm{hab} .)^{(11)}$ and abandonment $(9.1 \%)^{(34)}$. 
In summary, both QuantiFERON-TB Gold In TUBE® and TST have proven effective for the diagnosis of LTBI in household contacts of patients with active TB; both exhibit excellent sensitivity, specificity, predictive values, and accuracy. The concordance between these tests was moderate; the simplicity and low cost of TST indicate it is a good option for LTBI screening in sites with high TB prevalence and a history of childhood BCG vaccination. Thus, the diagnosis of LTBI by TST is proved to be effective and the initiation of treatment for latent forms of TB can prevent the active forms of the disease resulting impact on reducing morbidity and mortality from TB.

\section{ACKNOWLEDGMENTS}

We wish to thank the Graduate Program in Public Health at the Federal University of Maranhão and the Epidemiology of Communicable Diseases Research Group of the Federal University of Maranhão for study design and support.

\section{CONFLICT OF INTEREST}

The authors declare that there is no conflict of interest.

\section{FINANCIAL SUPPORT}

Foundation for Research and Scientific and Technological Development of Maranhão.

\section{REFERENCES}

1. World Health Organization (WHO). Global Tuberculosis Control: surveillance, planning, financing. WHO Report; 2008.

2. Dye C, Scheele S, Dolin P, Pathania V, Raviglione MC. Global burden of tuberculosis. Estimated incidence, prevalence, and mortality by country. JAMA 1999; 282:677-686.

3. Sociedade Brasileira de Pneumologia e Tisiologia. Sociedade Brasileira de Infectologia. Sociedade Brasileira de Reumatologia. Participantes: Conde MB, Mello F, Lima MA, Guerra RL, Miranda SS, Galvão TS, Pinheiro VG, Laurindo IM, Carvalho NB. Tuberculose infecção latente: diagnóstico (Elaboração Final: 31 de janeiro de 2011). Diretrizes Clínicas na Saúde Suplementar. Associação Médica Brasileira e Agência Nacional de Saúde Suplementar; 2014. 14p.

4. Comstock GW. How much isoniazid is needed for prevention of tuberculosis among immunocompetent adults? Int J Tuberc Lung Dis 1999; 3:847-850.

5. Pai M, Menzies D. Diagnosis of latente tuberculosis infection (tuberculosis screening) in HIV-negative adults: Systematic review. Uptodate 2014. (Accessed 2015 March 12). Available at www.uptodate.com

6. Golub JE, Bur S, Cronin WA, Gange S, Baruch N, Comstock GW, et al. Delayed tuberculosis diagnosis and tuberculosis transmission. Int J Tuberc Lung Dis 2006; 10:24-30.

7. Rose CE Jr, Zerbe GO, Lantz SO, Bailey WC. Establishing priority during investigation of tuberculosis contacts. Am Rev Respir Dis 1979; 119:603-609.
8. Ferreira CMP. Estudo da aplicabilidade de testes sorológicos no diagnóstico da tuberculose em Portugal: o caso particular da tuberculose latente. 2008. 93p. (Master's Dissertation). Universidade de Aveiro; 2008 Aveiro.

9. Lienhardt C, Fielding K, Hane AA, Niang A, Ndao CT, Karam F, et al. Evalution of the prognostic value of IFN-y release assay and tuberculin skin test in household contacts of infectious tuberculosis cases in Senegal. PLos Med 2010; 5:1-10.

10. Caglayan V, Ak O, Dabak G, Damadoglu E, Ketenci B, Ozdemir $\mathrm{M}$, et al. Comparison of tuberculin skin testing and QuantiFERONTB gold-In Tube test in health care workers. Tuberk Toraks 2011; 59:43-47.

11. Ministério da Saúde(MS). Secretaria de Vigilância Epidemiológica. Manual de recomendações para o controle da tuberculose no Brasil. Brasília: MS; 2011.

12. Aagaard C, Brok I, Olsen A, Ottenhoff TH, Weldingh K, Andersen P. Mapping immune reactivity towards Rv2653 and Rv2654: two novel low-molecular-mass antigens found specifically in the Mycobacterium tuberculosis complex. J Infect Dis 2004; 189:812-819.

13. Dinnes J, Deeks J, Kunst H, Gibson A, Cummins E, Waugh N, et al. A systematic review of rapid diagnostic tests for the detection of tuberculosis infection. Health Technol Assess 2007; 11:1-196.

14. Mazurek GH, Jereb MDJ, LoBue P, Michael F, Metchock B, Vernon A. Guidelines for using the Quantiferon-TB Gold test for detecting Mycobacterium tuberculosis infection, United States. MMWR Recomm Rep 2005; 54:49-55.

15. Pai M, Riley LW, Colford JM Jr. Interfero-gama assays in the immunodiagnosis of tuberculosis: a systematic review. Lancet Inf Dis 2004; 4:761-776.

16. Pai M, Menzies D. Interferon-gama release assays for diagnosis of latente tuberculosis infection: Systematic review. Uptodate 2014. (Accessed 2015 March 12). Available at www.uptodate.com

17. Cellestis Limited, Australia e Cellestis GmbH. QuantiFERON-TB Gold: Método in tubo, Teste de interferon-gama para sangue total, para medição de respostas aos péptidos antigénicos ESAT-6, CFP-10 \& TB7.7, Folheto informativo para diagnóstico in vitro. Hannover, Germany: ellestis Limited, Australia e Cellestis GmbH; 2009.

18. Landis JR, Koch GG. An application of hierarchical kappa-type statistics in the assessment of majority agreement among multiple observers. Biometrics 1977; 33:363-374.

19. Takenami I, Loureiro C, Machado A Jr, Emodi K, Riley LW, Arruda S. Blood cells and interferon-gamma levels correlation in latent tuberculosis infection. ISRN Pulmonology 2013; 2013:1-8.

20. Machado A Jr, Emodi K, Takenami I, Finkmoore BC, Barbosa T, Carvalho J, et al. Analysis of discordance between the tuberculin skin test and the interferon-gamma release assay. Int $\mathrm{J}$ Tuberc Lung Dis 2009; 13:446-453.

21. European Centre for Disease Prevention and Control (ECDC). Use of interferon-gamma release assays in support of TB diagnosis. Stockholm: ECDC; 2011.

22. Metcalfe JZ, Everett CK, Steingart KR, Cattamanchi A, Huang $\mathrm{L}$, Hopewell PC, et al. Interferon- $\gamma$ release assays for active pulmonary tuberculosis diagnosis in adults in low- and middleincome countries: systematic review and meta-analysis. J Infect Dis 2011; 204:1-10.

23. Sester M, Sotgiu G, Lange C, Giehl C, Girardi E, Migliori GB, et al. Interferon- $\gamma$ release assays for the diagnosis of active tuberculosis: a systematic review and meta-analysis. Eur Respir J 2011; 37: 100-111.

24. Rangaka MX, Wilkinson KA, Glynn JR, Ling D, Menzies D, Mwansa-Kambafwile J, et al. Predictive value of interferon- $\gamma$ release assays for incident active tuberculosis: a systematic review and meta-analysis. Lancet Infect Dis 2012; 12:45-55. 
25. Machado PC, Valim ARM, Maciel ELN, Prado TN, Borges TS, Daronco A, et al. Comparação do teste tuberculínico e do ensaio de liberação de interferon-gama para diagnóstico de tuberculose latente em agentes comunitários de saúde do Sul do Brasil, Rio Grande do Sul, 2012. Epidemiol Serv Saude 2014; 23:675-681.

26. Menzies D, Pai M, Comstock G. Meta-analysis: new tests for the diagnosis of latent tuberculosis infection: areas of uncertainty and recommendations for research. Ann Intern Med 2007; 146:340-354.

27. Rosemberg J. Mecanismo imunitário da tuberculose: síntese e atualização. Boletim de Pneumologia Sanitária 2001; 9:35-59.

28. Zwerling A, Behr M, Verma A, Brewer T, Menzies D, Pai M. World Atlas of BCG Vaccination Policies and Practices. 2015 (Accessed 2012 March 15). Available at: http://www.bcgatlas.org.

29. Menzies D, Gardiner G, Farhat M, Greenaway C, Pai M. Thinking in three dimensions: a web-based algorithm to aid the interpretation of tuberculin skin test results Int J Tuberc Lung Dis 2008; 12:498-505.

30. Lee SW, Oh DK, Lee S, Kang HY, Lee CT, Yim JJ. Time interval to conversion of interferon-gamma release assay after exposure to tuberculosis. Eur Respir J 2011; 37:1447-1452.
31. Adetifa IM, Ota MO, Walther B, Hammond AS, Lugos MD, Jeffries DJ, et al. Decay kinetics of an interferon gamma release assay with anti-tuberculosis therapy in newly diagnosed tuberculosis cases. PLoS One 2010; 5:e12502.

32. Gazetta EC, Ruffino-Netto A, Pinto Neto JM, Santos MLSG, Cury MRCO, Vendramini SHF, et al. O controle de comunicantes de tuberculose no programa de controle da tuberculose em um município de médio porte da Região Sudeste do Brasil, em 2002. J Bras Pneumol 2006; 32:559-565.

33. Kipfer B, Reichmuth M, Büchler M, Meisels C, Bodmer T. Tuberculosis in a Swiss army training camp: contact investigation using an Interferon gamma release assay. Swiss Med Wkly 2008; 138:267-272.

34. Silva PF, Moura GS, Caldas AJM. Fatores associados ao abandono do tratamento da tuberculose pulmonar no Maranhão, Brasil, no período de 2001 a 2010. Cad Saude Publica 2014; 30:1745-1754. 